\title{
Design of Flip Class Based on Moso Teach
}

\author{
Ying Liu, Hongjuan Song, Yan Zhao, Fengying Zheng, Xinru Pang
}

Department of Medicine, Binzhou Polytechnic, 256603, China

Email: 359292773@qq.com

Keywords: Moso Teach; Flip Class; Teaching Design

\begin{abstract}
As information technology enters the field of education, the traditional teaching mode is changed. According to the characteristics of Moso Teach mobile, interactive, real-time, big data feedback, This article discusses how to collect and produce teaching resources, design suitable teaching activities such as group assignments, test, brainstorming discussion and answering questions, strengthen teaching management through check-in, sending messages, questionnaires to mobilize students' initiative, enthusiasm and creativity, to become the protagonists of learning.
\end{abstract}

\section{Introduction}

On May 23, 2015, Chinese President Xi Jinping pointed out in the opening speech of the first international education information conference in Qingdao that it is necessary to build a learning society that "everyone can learn, everywhere can learn, and every minute can learn", and actively promote the integration and innovation of information technology and education [1].

Information technology can't change the nature of education, but it can change the teaching mode by changing the presentation mode of each link in the teaching process. Flipped class is a new educational model brought by information technology. However, there are some unsatisfactory aspects in the application of flipped class. Moso Teach was born to solve these problems. Moso Teach is a free teaching assistant APP launched by mosoink technology Co. Ltd. It is a teaching cloud service platform that uses mobile intelligent devices to conduct real-time interactive feedback inside and outside the classroom in the network environment [2]. According to the characteristics of real-time, interactive and data feedback of Moso Teach, the author designed teaching activities with flipped class model and gained a lot.

\section{Production and release of teaching resources}

According to the teaching content and objectives teachers should produce different types of teaching resources for students to learn. First teachers should provide a learning clues-the framework of mind mapping. At the beginning of self-study, student often feels unable to start, do not know how to summarize. Teachers can design a less difficult way: leave a critical position in the mind map, and let students find the answer from the textbook and fill in the blank; then gradually increase the difficulty: teachers provide options for students to organize by themselves according to the content of the textbook; and finally the students carry out all by themselves. Students gradually learn how to summarize and how to make knowledge clear in repeated training. In addition to the design mind map clues the teaching resources also include a variety of learning materials pushed to the students: micro class, videos, pictures, animations and other forms of images to help students understand the abstract content. Students can use their mobile phones to learn anywhere and at any time. Teachers can check the learning progress of each student through the platform, timely urge and effectively monitor extra-curricular learning [3].The preparation of these materials requires a lot of time and energy of teachers and the strength of the teachers is limited. In addition to forming a team of teachers students' associations student assistants and intern students can be mobilized to collect and sort out materials. 


\section{Design of Teaching activity}

\subsection{Group assignments}

Mind mapping is a theoretical group task completed by the team members in collaboration with each other. Students in higher vocational colleges have poor learning foundation, are accustomed to passive acceptance of knowledge, lack of initiative in learning, often retreat in the face of difficulties, even bored and depressed. The cooperation of mind maps encourages the team members to help each other, make progress together, gradually enhance the learning confidence, and cultivate the learning interest and teamwork spirit in the sense of gain.

The experimental work is also done in groups. Students can upload video and pictures taken in the experiment to Moso Teach. Not only can the experimental results be seen, but problems in the process can also be found in video, avoiding the disadvantages of traditional experimental work. In order to get excellent team performance, the team members will take the initiative to explain and correct operations to each other, and consciously realize the peer education.

Mind map group assignments can be assessed in a form of defense. Teachers can choose examiners to find out the questions in the mind map by means of raising their hands, selecting candidates, and answering questions. All team members can participate in the defense. According to the completion of the mind map and the performance of the defense, the corresponding group evaluation will be given, and the teachers will reward the examiners for their good questions. Teachers only make appropriate comments in the defense, select key and difficult points to explain, not as protagonist, only as a supplement.

Group assignments can also be evaluated by anonymous student evaluations, intra-group evaluations, teacher evaluations, or free combinations of these evaluations, according to the grading standards set by teachers. Adjusting the proportion of various evaluations can not only examine the team's cooperation achievements but also reflect the role of the individual, make the results more fair and reasonable. On the one hand students' participation in evaluation can reduce the workload of teachers, on the other hand students find various problems in the homework from the perspective of teachers so as to improve the quality of work.

\subsection{Tests}

The author designed two kinds of tests. A guided test that has no time limit and only a deadline for completion. Students discuss and complete the guided test in the group after the completion of the mind map. That encourages students to teach and learn from each other, pool their ideas, promote the progress of slow students and strengthen team cohesion. The purpose of the guided test is to deepen the memory, understanding and consolidation of the textbook knowledge. Therefore, teachers should carefully design the test questions to cover all knowledge. After several tests in the group, students have to review the textbooks and other learning resources repeatedly to find out the neglected contents, to find out the mistakes and correct them so as to deepen their understanding in the continuous improvement of their scores. According to the analysis results of Moso Teach statistics, teachers can find common problems for key explanation and improve class utilization. The other test is defined as an effect test. The next class will take place, leaving the students with time to digest and absorb the knowledge. the effect test is designed for a limited time to assess student mastery. Every student's test questions will be in any order and random that can truly test the learning effect of every student, avoid making up the number.

\subsection{Discussion and answers questions}

At the beginning of discussing the Q\&A, students are often not good at asking questions let alone discussing them. In the previous guided test, students often encounter problems that cannot be solved by the group. The author then conducts a discussion and answers questions about these questions in the whole class. In order to encourage students to participate actively, each speech is rewarded with experience value. Valuable questions and answers can be rewarded with additional experience value to encourage students to express their unique views and form creative and critical thinking. Students look at questions from a variety of angles, and often give some answers that 
teachers do not take into account.

\subsection{Brainstorming}

The test can be designed only two types of questions: selection and judgment. Some open questions such as case analysis and morphological identification can be carried out in brainstorming activities. The characteristic of brainstorming is that students can't see other people's answers in activities, only share them after the activity is over. They can avoid being disturbed by others and express their independent opinions. Brainstorming has no option reference and can test the deviation of students' understanding of knowledge. However, the answer is highly discrete and the intelligent tag function of Moso Teach can be used to lock several alternative answers to focus on discussion. Teachers can monitor everyone's answers at any time, find out the problems and summarize them in time, and reward different experience values according to the response.

\section{Design of teaching management}

\subsection{Check-in}

Attendance is the guarantee of classroom activities and an important means of classroom management. Moso Teach designed two check-in methods. One-click check-in is convenient and quick. Students can finish it in a few seconds after they are ready, but absent students is easy to be take advantage of this method to sign in. Gesture sign-in can be designed with complex graphics by imitating it for students to sign in. It is difficult for students who skip class to imitate within a time limit of ten seconds. After signing in. Moso Teach will automatically put the list of students who are absent from class at the top, so that teachers can manually set the reasons for absence and students who are not signed conveniently. GPS can also locate students' locations, and teachers can pay more attention to students with abnormal positions in class to determine whether they are attending.

\subsection{Messages}

Teachers can send messages to all students by releasing class notices. Moso Teach can automatically count the number of students who have been and have not been checked to facilitate individual reminders. Teachers can also initiate private chat with a student individually, respecting the privacy and self-esteem of the student, and avoiding rebellious psychology.

\subsection{Questionnaire}

The questionnaire can count students' opinions, suggestions and learning difficulties. The questionnaires are anonymous and students can express their ideas boldly. After the end of the activity, Moso Teach will immediately generate accurate statistical data and feedback to teachers in time to select key and difficult teaching contents or to adjust appropriate teaching methods and activity settings according to the statistical results.

\section{Reflection}

Moso Teach provides a new idea and direction for the reform of information teaching. Teachers should change their concepts conform to the requirements of our times, accept and try new information technology, and study in exploration. Teachers not only need to collect and produce a large number of teaching resources and design appropriate teaching activities, but also need to take more spare time to interact with students, supervise them and give feedback timely, so that students can feel that teachers are with them [4].

The solidified thinking of students needs to be changed more. From childhood to college students are accustomed to accepting the knowledge taught by the teachers. The self-control is poor and the self-learning consciousness is weak. Teachers should give action and emotional support and encouragement, gradually cultivate students' independent learning habits, stimulate students' internal learning motivation, and make students the protagonists of learning truly [5]. 


\section{Acknowledgement}

In this paper, the research was sponsored by Project of Scientific Research of Binzhou Polytechnic (Project No. 2013XYKT121).

\section{Reference}

[1] Xinhuanet. Congratulatory letter from Xi Jinping to the International Education Informatization Conference [DB/OL]. http://news.xinhuanet.com/ politics/ 2015-05/23/c_1115383960.htm.

[2] Yue Han, Yi Wang. In-depth Research based on Moso teach APP [J]. Journal of Educational Technology, 2017, 16(7): 87-89.

[3] Yinyin Zhang, Yanbin Niu. Application of Mobile Teaching Platform in Higher Education Teaching [J]. Journal of Educational Technology,2017, 16(3): 23-24

[4] Qian Zheng, Hua Liu, Xiuwei Li, et al. Reasonable use of moso teach to carry out functional experiment teaching practice of information [J/OL]. Sichuan Journal of Physiological Sciences, 2018(03):1-7[2018-07-31].http://kns.cnki.net/kcms/detail/51.1160.R.20180409.1114.002.html.

[5] Bai-yu Li, Jun Zhou, Yanfang Huang. The Construction of Hybrid Teaching Model Based on the course of Pharmaceutical Analysis Technology [J]. Journal of Nantong Vocational University, 2017, 31(4):53-56. 